\title{
ONOMÁVEIN
}

Revista de lingüística, filología y traducción

\section{Mme d'Aulnoy y su contribución al desprestigio de España en Europa: Relation du voyage en Espagne (1691)}

Mme d'Aulnoy and her contribution to the disrepute of Spain in Europe: Relation du voyage en Espagne (1691)

\section{Ángeles García Calderón}

Universidad de Córdoba

ONOMÁZEIN | Número especial VII - Discurso turístico, lenguas y traducción: 108-126

DOI: 10.7764/onomazein.ne7.07

ISSN: 0718-5758

\section{(C) $(1) \odot$}

Ángeles García Calderón: Departamento de Ciencias Sociales, Filosofía, Geografía, Traducción e Interpretación. Universidad de Córdoba. | E-mail: idlgacaa@uco.es

Fecha de recepción: diciembre de 2019

Fecha de aceptación: mayo de 2020 


\section{Resumen}

La escritora normanda Marie-Catherine le Jumelle de Barneville (1651-1705), más conocida en el mundo de las letras como Madame d'Aulnoy, publicaría en 1691 Relation du voyage en Espagne. En el libro narra sus impresiones de un viaje a nuestro país, que debió llevar a cabo entre 1678 y 1690 .

Obra muy alabada en el siglo XIX por los intelectuales franceses, es claro que su difusión contribuyó al descrédito de España, en Francia y en buena parte de Europa, por lo pormenorizado y exhaustivo, aunque parece estar provista de buena parte de exageración debido a diferentes motivos: sentirse abandonada al comienzo de su periplo por su guía francés, como narran documentos alusivos al viaje (lo cual le agriaría el carácter y le haría ver todo de un modo más exagerado de lo normal); bien por no sentirse satisfecha con el trato recibido por parte de sus iguales; quizá porque las costumbres le parecieran muy diferentes a las de su país; posiblemente el carácter del pueblo español, menos artificial, en general, que el del francés, le pareciera vulgar y poco refinado, etc. etc.

Palabras clave: España; siglo XVII; Mme d’Aulnoy; literatura de viajes.

\section{Abstract}

The Normandy-born writer, Marie-Catherine le Jumelle de Barneville (1651-1705), better known as Madame d'Aulnoy in the circles of Arts, published Relation du Voyage en Espagne, in 1691. This book gathers her impressions of a journey to our country, which she probably made between the years 1678 and 1690 .

The widely known work has been highly praised in the 19th century by French intellectuals, and it seems that it had contributed a great deal to the disrepute of Spain, not only in France but also in other European countries. Apparently, this may be due to various reasons, not a lesser one being the notable hyperbolic character of her discourse at various stages of the work: firstly, her increasing bitterness of character, which some attach to the sudden breaking off of her sentimental relationship to her French guide, as stated in some documents referring to her trip; also, because she did not feel happy with the treatment provided by her foreign peers, whose customs seemed to her too different to those of her own; or perhaps and not less relevantly because of the wide cultural gap existing between the Spaniards and the natives of her own country, in such questions as custom refinement, artificiality in personal treatment and so on.

Keywords: 17 th century Spain; Mme d’Aulnoy; travel literature. 


\section{Introducción}

A la escritora normanda Marie-Catherine le Jumelle de Barneville (1651-1705), más conocida en el mundo de las letras como Madame d'Aulnoy por su casamiento con el barón d'Aulnoy en Brie, le cabe el dudoso honor de haber contribuido al descrédito de España, en Francia y en buena parte de Europa, debido a la publicación en 1691 de su Relation du voyage en Espagne, en el que narra sus impresiones de un viaje anterior a nuestro país, por el que debió viajar entre 1679 y 1680. Este viaje, que sería objeto de controversia durante un tiempo hasta llegar a admitirse su veracidad, contribuiría en gran medida a formar una pésima opinión de España en los viajeros extranjeros, dada la gran difusión que tuvo el libro, que por otra parte sería muy alabado por los intelectuales franceses, ya fueran estos periodistas, filósofos, novelistas, poetas o historiadores. Tres ejemplos bastan para mostrar la atracción y admiración que despertaría la obra en Francia, no solo en el momento de su publicación (1691), sino en todo el siglo XIX, como atestiguan las opiniones de figuras tan importantes como Charles Augustin Sainte-Beuve (quien recomendaría el libro de Aulnoy para comprender los textos españoles que estaban de moda en Francia), Jules Barbey d’Aurevilly (que consideraría la obra como una de las evocaciones más brillantes de España), Hypolitte Taine (que recomendaría a los franceses la lectura del libro para conocer el carácter español); veamos la de este último.

L'ESPAGNE EN 1679
On imprime beaucoup de livres nouveaux; on fe-
rait bien de réimprimer quelques livres anciens,
au premier rang celui-ci. D’abord il est bien écrit;
Mme d'Aulnoy est du grand siècle littéraire; elle
appartient au meilleur monde; elle parle avec
justesse et naturel; elle n'est point prude, philo-
sophe ou pédante; elle est exempte de toute af-
fectation; elle observe sans effort, blâme ou loue
avec discrétion et mesure; elle n'exagère jamais,
elle ne croit ni ne veut faire un chef-d'œuvre; son
récit semble un entretien; elle a toutes les qua-
lités d'une Française bien douée et bien élevée,
bon sens, liberté d'esprit, tact sûr, grâce un peu
moqueuse, politesse aisée et continue. D'autre
part, elle voit l'Espagne à un moment curieux
de son histoire: c'est la fin d'une grande époque;
le dernier descendant de Charles-Quint est roi;
après lui, la nation, sous une nouvelle dynastie,
entrera dans une nouvelle carrière. D’ordinaire,
on ne connaît l'Espagne que par son drame, ses
romans picaresques et sa peinture; quand, sur
de tels documents, on essaye de se figurer la vie

ESPAÑA EN 1679

Se imprimen muchos libros nuevos; haríamos bienen reimprimiralgunos viejos, esteel primero. Ante todo, está bien escrito; Mme d’Aulnoy vivió en el Gran Siglo literario; pertenece a la mejor sociedad; escribe con exactitud y naturalidad; no es mojigata, filósofa

ni pedante; está libre de afectación, observa sin esfuerzo, culpa o elogia con discreción y moderación; nunca exagera, no cree ni quiere hacer una obra maestra; su relato parece una conversación; tiene todas las cualidades de una francesa de talento y bien educada, sentido común, libertad de espíritu, delicadeza, gracia algo burlona, cortesía fácil y continua. Por otro lado, ve España en un momento curioso de su historia: es el final de una gran época; el rey es el último descendiente de Carlos V; después de él, la nación, bajo una nueva dinastía, entrará en una nueva era. Habitualmente, España es conocida sólo por su teatro, sus novelas picarescas y su pintura; cuando, en tales documentos, uno intenta imaginar la vida real, duda y no se atreve 
réelle, on hésite et on n'ose conclure; de pareilles mœurs semblent fabuleuses. Après avoir lu ce voyage, on les voit et on les touche, telles que les arts les avaient représentées; ni les livres ni les tableaux n'avaient menti; les personnages de Lope, de Galderon (sic), de Murillo et de Zurbaran couraient les rues. Le lecteur va juger du caractère espagnol, non d'après les œuvres d'imagination qui le mettent en scène, mais d'après un témoin qui l'a vu.

(http://obvil.sorbonne-universite.site/corpus/ critique/taine_derniers-essais/) a sacar conclusiones; costumbres semejantes parecen fabulosas. Tras leer este viaje, se ve y se siente a los españoles, tal como las artes los habían representado; ni los libros ni los cuadros habían mentido; los personajes de Lope, de Calderón, de Murillo y de Zurbarán pululaban por las calles. El lector va a juzgar el carácter español, no según las obras de imaginación que lo escenifican, sino por un testigo que lo ha visto. ${ }^{1}$

El prestigioso historiador, autor en 1853 de una importante "Thèse d’État": Essai sur Les Fables de La Fontaine, por seguir el símil del título de su tesis, parece fabular en su juicio sobre el libro de su compatriota al autentificar lo que ella escribe sobre los españoles, y a cuyos escritores y pintores más importantes Taine no parece conocer muy bien, ya que escribe mal dos de los cuatro apellidos citados. Se puede pensar, como es lo más lógico, que él mismo tuviera ya prefijada una opinión tan negativa respecto de España y los españoles como la de Mme d’Aulnoy, la cual veremos por los fragmentos o pasajes que citaremos en la estructura y descripción del libro en cuestión.

\section{Recepción de la obra: la cuestión de la veracidad}

El hecho de que se trate de un trabajo sobre viajes de una escritora francesa no es óbice para que dos investigadoras en las geografías británicas del siglo XVIII nos sirvan para introducir la difusión y repercusión del libro de Mme d’Aulnoy, objeto de nuestro estudio, publicado en 1691: Relation du voyage en Espagne.

La primera de ellas trata el asunto en un artículo de 1994; veamos la cita alusiva:

Efectivamente, España no interesaba a los británicos y, aunque en el siglo XVIII se lanzaron a viajar por Europa en lo que luego se dio en Ilamar el "Grand Tour”, la Península quedó marginada del circuito. En consecuencia nadie la visitó con el ánimo de hacer "turismo" y nada nuevo se publicó sobre ella. De modo que los editores no encontraron fuentes de información que estuvieran al día y tuvieron que limitarse a publicar los viejos relatos, o basarse en ellos para sus textos, lo cual fosilizó la vieja y negativa imagen que España tenía, cosa que, a su vez, como reconocen los propios editores, desanimó a posibles futuros viajeros. [...]

1 En este y en todos los ejemplos traducidos, a no ser que se explicite, la traducción es mía. 
Sin embargo el problema de los editores se complica no sólo debido al uso de fuentes que, con el tiempo, fueron quedando anticuadas sino que, sin saberlo, están utilizando relaciones de viaje que la crítica posterior ha considerado falsos. Esto sucede con Relation du Voyage d'Espagne de la condesa d'Aulnoy, libro que fue muy popular en Inglaterra y que, traducido por primera vez en 1692, alcanzó su onceava edición en 1808 y con Memoirs of an English officer including anecdotes of the war in Spain under the earl of Peterborough que se consideraba escrita por un capitán del ejército Ilamado George Carleton y que la crítica moderna ha adjudicado a Daniel Defoe, autor muy experto en esconderse bajo innumerables nombres.

Efectivamente, el hispanista Foulché-Delbosch, que estudió con profundidad el texto de la condesa d’Aulnoy, llegó a la conclusión de que no sólo era falso el relato, sino que la escritora nunca había estado en España. Según este historiador, d’Aulnoy utilizó como fuentes libros de otros viajeros franceses, cartas privadas a las que tuvo acceso y conversaciones con personas que conocían bien el país; posteriormente, fundió estos materiales, los unificó con un estilo novelesco, recordemos que la condesa fue también escritora de cuentos, y, reforzando los elementos románticos y exóticos, lo envolvió todo en una atmósfera mágica que hacía del texto una narración realmente atrayente. Delbosch consideraba que su falsedad no se había establecido definitivamente hasta 1865, a pesar de que muchos autores del siglo XVIII, como Clarke que lo calificaba de "libro pirateado de un escritor francés", ya habían puesto en duda su autenticidad. Sin embargo este texto, que, probablemente, colaboró a crear la imagen de un país exótico y romántico, fue utilizado por muchos de los redactores del siglo XVIII que lo citan como fuente de información.

El cliché, pues, está servido y lo que hacen las geografías y enciclopedias no es más que perpetuarlo: España, mero apéndice de los borbones franceses, es un país pobre y despoblado que se halla en plena decadencia; sus habitantes perezosos y orgullosos, fanáticos y lascivos, están dominados por los celos y el deseo de venganza; dormitando al sol en invierno y a la sombra de una iglesia en verano, hacen su siesta diaria, asisten a su misa y dejan que los franceses hagan todo.

Ya lo había dicho Daniel Defoe en un poema satírico que escribió en 1701:

"Orgullo, el primer caballero, y Presidente del Infierno, sobre España, su parte y mayor provincia, cayó.

El sutil Príncipe creyó conveniente darles las ricas minas de oro de Méjico; y todas las montañas de plata de Perú;

Riqueza que en manos prudentes podría dominar el mundo:

pero él sabía que su temperamento era este: demasiado perezosos y demasiado altivos para ser ricos.

Un pueblo tan orgulloso, tan por encima de su destino, que, si reducido a pedir, lo haría con arrogancia.

Malgastan su dinero para que se les Ilame valientes y, orgullosamente, mueren de hambre porque desprecian el ahorro.

Nunca hubo una nación en el Mundo que fuera tan rica y, sin embargo, tan pobre” (Freixa, 1994: 59-79).

La segunda cita es de 2004:

La geografía era la ciencia de moda en la Gran Bretaña del siglo XVIII, y esto tuvo su reflejo en la publicación de infinidad de obras, sobre el tema, tanto eruditas como de divulgación. Los editores publicaban colecciones que, bajo el título de geografías, ofrecían una recopilación de relatos obte- 
nidos de los libros de viaje de los británicos, que vieron en Europa y en el Mediterráneo el perfecto destino para sus viajes de estudios, lo que se conocía como el "Grand Tour".

Sin embargo, la península Ibérica no estaba incluida en este circuito cultural y turístico, al menos durante los dos primeros tercios del siglo XVIII. Quedó marginada de tal modo que no llegaban a nuestras tierras viajeros con intención de hacer turismo. En consecuencia, tampoco se publicó nada nuevo sobre España, favoreciendo así el caldo de cultivo de numerosos tópicos y clichés acerca de los españoles. Para los británicos del XVIII España es pobre, despoblada y en plena decadencia; un mero apéndice de los borbones franceses. Sus habitantes son perezosos, orgullosos, dominados por los celos y el deseo de venganza; siempre dormitando al sol de invierno y a la sombra de una iglesia en verano. Su única preocupación es hacer su siesta diaria, asistir a misa y dejar que los franceses lo hagan todo. Daniel Defoe escribiría un poema satírico en 1701 que refleja esta concepción de los españoles:

"Orgullo, el primer caballero, y Presidente del Infierno, sobre España, su parte y mayor provincia cayó. / El sutil Príncipe creyó conveniente darles las ricas minas de oro de Méjico; y todas las montañas de plata de Perú; / Riqueza que en manos prudentes podría dominar el mundo: I Pero él sabía que su temperamento era este: demasiado perezosos y demasiado altivos para ser ricos. Un pueblo tan orgulloso, tan por encima de su destino, que si reducido a pedir, lo haría con arrogancia. / Malgastan su dinero para que se les llame valientes y, orgullosamente, mueren de hambre porque desprecian el ahorro. / Nunca hubo nación en el Mundo que fuera tan rica y, sin embargo, tan pobre” (Martínez, 2004)².

Las dos geógrafas, Freixa y Martínez, se apoyan en un poema del año 1701, del inglés Daniel Defoe, en el que se critica el carácter y la idiosincrasia del pueblo español. Dado que la traducción que citan como prueba es la misma en los dos casos, es fácil deducir que la segunda es una reproducción ad pedem litterae de la primera, aunque la versión no sea muy afortunada, como podemos apreciar al transcribir el poema de Daniel Defoe y su traducción. Con el poema titulado The True-Born Englishman, Defoe tomaba partido por el que era en ese tiempo rey de Inglaterra, Escocia e Irlanda, el holandés Guillermo III, por su casamiento con María II de Inglaterra, desde 1689 hasta 1702, reinando solo a la muerte de ella en 1694. El escritor lo defendía contra los ataques xenófobos de sus enemigos políticos y ridiculizando la noción de pureza racial inglesa, haciéndose el poema popular con gran rapidez. Veamos el fragmento y una traducción más ajustada que la propuesta:

2 Sabido es que el "Grand Tour" al que hace referencia Martínez era un periplo por Europa que se desarrolló desde la década de 1660 hasta el comienzo del ferrocarril; consistía en su origen en un largo viaje llevado a cabo por los jóvenes de las clases altas de la sociedad europea, sobre todo de la británica, sirviendo como un rito de formación y de madurez. Podía llevar desde varios meses a varios años, aunque lo normal es que durara uno como mucho, y se realizaba tras la finalización de los estudios. Los destinos principales eran Francia, los Países Bajos, Alemania, Suiza y sobre todo Italia; más tarde se añadió Grecia y Asia Menor. En los siglos XVIII y XIX el "Grand Tour" fue privilegio de los aficionados al arte, coleccionistas y escritores (Goethe y Alejandro Dumas entre los más conocidos). El viaje ponía en contacto a la alta sociedad de Europa del Norte con el arte antiguo y posibilitaba al que lo llevaba a cabo el convertirse en un perfecto "gentleman", sirviendo también para la formación política y la educación sexual del viajero. 
THE TRUE-BORN ENGLISHMAN

Pride, the first peer, and president of Hell, To his share Spain, the largest province, fell. The subtile Prince thought fittest to bestow On these the golden mines of Mexico, With all the silver mountains of Peru, Wealth which would in wise hands the world undo:

Because he knew their genius was such, Too lazy and too haughty to be rich. So proud a people, so above their fate, That if reduced to beg, they'll beg in state; Lavish of money to be counted brave, And proudly starve because they scorn to save.

Never was nation in the world before So very rich and yet so very poor.
EL INGLÉS BIEN NACIDO

El Orgullo, primus inter pares, y presidente del Infierno,

en cuya posesión cayó España, la región más grande. El sutil Príncipe pensó sería lo más conveniente otorgarles las minas de oro de México, junto con las montañas de plata del Perú, riquezas que en manos sabias desharían el mundo: porque él sabía que tal era el genio de ellos, perezosos y altaneros en demasía para ser ricos. Gente tan orgullosa, tan por encima de su destino, que, obligados a mendigar, pedirían en rango; Pródigos en dinero para ser tenidos por valientes, y con orgullo pasarían necesidad por negarse a ahorrar.

Nunca hubo nación antes en el mundo tan rica, y sin embargo tan pobre al mismo tiempo.

Por lo que se refiere a la cuestión de la veracidad del viaje a España de Mme d'Aulnoy, Consol Freixa concede una total credibilidad al juicio de Foulché-Delbosch (que ella escribe sin guion), al admitir con este la falsedad del relato de Mme d’Aulnoy. Pero, algunos años más tarde, Losada Goya refutaría esta teoría:

Rappelons un vieux débat sur l'authenticité du voyage de Mme d'Aulnoy en Espagne. Le point de départ est un article très argumenté de Foulché-Delbosch [...]. Enfin, outre qu'aucun de ses contemporains n'a mis ce voyage en doute, on connaît les lieux où la comtesse se trouvait dans chaque année depuis 1670 à 1685 sauf pour les années 1679-1681, c'est-à-dire, précisement l'époque du voyage. Revenant sur la question, Miguel Lasso de la Vega a rappellé à la fois l'exagération de la voyageuse et le motif qui poussa Foulché-Delbosch à vouloir prouver que ce voyage n’avait jamais existé: son inimitié vers Morel-Fatio, qui soutenait le contraire. (Losada Goya, 1999: 539-540).
Recordemos un viejo debate sobre la autenticidad del viaje de la Sra. d'Aulnoya España. El punto de partida es un artículo muy bien argumentado de Foulché-Delbosch [...]. Por último, aparte del hecho de que ninguno de sus contemporáneos cuestionó este viaje, conocemos los lugares en los que la condesa estuvo cada año de 1670 a 1685, excepto los años 1679-1681, es decir, precisamente el momento del viaje. Volviendo a la pregunta, Miguel Lasso de la Vega recordó tanto la exageración del viajero como el motivo que llevó a Foulché-Delbosch a querer demostrar que este viaje nunca había existido: su enemistad con Morel-Fatio, que sostenía lo contrario.

Añado un argumento, no recogido hasta ahora y expuesto en 1936 por el historiador francés Paul Courteault, que, viendo el asunto con lógica, debe zanjar el debate: 
Un document récemment découvert par M.G. Ducaunnès-Duval, archiviste honoraire de la ville de Bordeaux, semble devoir trancher le debat. C'est un acte conservé aux archives départementales de la Gironde, dans les minutes du notaire Conilh. Il est daté du 19 décembre 1678. II conte le voyage mouvementé que Marie-Catherine Le Jumel de Bandeville, femme séparée de François de Lamothe, comte d'Aulnoy, contrôleur général de la maison du prince de Condé, fit de Paris à Bordeaux pour se rendre en Espagne. La voyageuse eut des difficultés avec le roiturier qui s'était chargé de la transporter, elle et son train. Au lieu de payer les dépenses, comme il s'y était engagé, il l'obligea à solder tous les frais de sejour aux différentes étapes, puis, à Poitiers, l'abandonna à son triste sort. Mme d'Aulnoy gagna Bordeaux par ses propes moyens et y fit constater par-devant notaire la façon dont elle avait été traitée. Le document ne paraît laisser aucun doute sur la réalité du voyage en espagne de l'auteur de la Relation. (Courteault, 1936: 384).
Un documento recientemente descubierto por M.G. Ducaunnès-Duval, Archivero Honorario de la Ciudad de Burdeos, parece zanjar el debate. Es un documento conservado en los archivos departamentales de Gironda, en las actas del notario Conilh. Está fechado el 19 de diciembre de 1678. Cuenta el agitado viaje que Marie-Catherine Le Jumel de Bandeville, separada de François de Lamothe, Conde de Aulnoy, Contralor General de la Casa del Príncipe de Condé, hizo de París a Burdeos para viajar a España. La viajera tuvo dificultades con el guía que se había encargado de transportarla a ella y a su séquito. En lugar de pagar los gastos, como se había comprometido a hacer, obligó a ella a hacerlo en las distintas etapas, y luego, en Poitiers, la abandonó a su triste destino. La Sra. d'Aulnoy fue a Burdeos por sus propios medios y dejó constancia ante notario del modo en que había sido tratada. El documento parece no dejar dudas sobre la realidad del viaje del autor a España.

No contradice lo afirmado por Courteault la opinión de dos prestigiosos historiadores españoles, Gabriel Maura y Gamazo (Duque de Maura) y Agustín González-Amézua, quienes en la introducción de un libro sobre el viaje de la escritora a Españả, Fantasías y realidades del viaje a Madrid de la Condesa d'Aulnoy, demuestran una gran solidez en sus afirmaciones, producto seguramente del cotejo de documentos en múltiples archivos. Veamos sus apreciaciones:

El viaje de Madame d'Aulnoy, emprendido apenas se firmó en Nimega la paz hispano francesa, aun antes de canjeadas las ratificaciones del Tratado, tuvo por objeto (aparte satisfacer su cariño filial reuniéndose durante una temporada con su madre, a quien no veía desde la corta visita que la pudo hacer en Inglaterra) encomendarla el cuidado, la educación y el ulterior matrimonio de la penúltima de sus hijas, Judit Enriqueta, ahijada suya, como lo indica el primer nombre, nacida en 14 de noviembre de 1669, el propio mes de la degollación de los calumniadores susodichos, cómplices de la fugitiva abuela, junto a la cual quedó la nieta en España después del retorno a Paris de su madre.

3 Madrid: Ed. Saturnino Calleja. La fecha de edición no ha puesto nunca de acuerdo a los estudiosos; en unos casos 1942, en otros 1943, 1944 ó 1949. En alguna ocasión, lo cual parece más lógico, se indica: s. f. (años 40). 
Tenemos la impresión de que el viaje desde la frontera hasta Madrid debió de ser tan lento y penoso como lo pondera su narradora, no siendo, en cambio, exacto, ni que lo hiciese en la compañía que dice, ni que conservase humor para visitar todos los monumentos que menciona.

Madame d’Aulnoy no comenzó a escribir para el público sino bastantes años después; pero frecuentaba ya el mundillo literario parisiense, donde los atractivos de su ingenio y las amabilidades de su trato le habían procurado sinceras y valiosas amistades. Es muy verosímil que se le hubiese encomendado la corresponsalía en Madrid (mientras permaneciese en nuestra Corte) de la Gazette, periódico fundado en 1631 por Teofrasto Renaudot para recoger y divulgar nuevas de todo el mundo, y que, medio siglo después, continuaba editando un descendiente suyo del mismo apellido. Diremos el fundamento de esta hipótesis nuestra. La Gazette de Renaudot venía apareciendo casi ayuna de informaciones españolas de actualidad, hasta que, desde fecha muy poco posterior al arribo a Madrid de nuestra viajera, comenzó a menudearlas, redactadas, además, en el inconfundible estilo propio de su pluma, como lo podrá advertir el lector en el texto de la Relation, donde se insertó reproducida, al cabo de once años, la mayor parte de ellas.

(http://www.bocos.com/dw_un_viaje_por_espana_1679/Un_viaje_por_ESPANA_en_\%201679.pdf.)4.

En otro párrafo, de la misma introducción, los historiadores aportan un interesante juicio sobre el interés que suscitó la obra, sus reproducciones y traducciones:

Aunque gran parte de esa obra conserva interés asombrosamente perdurable al cabo de dos siglos y medio, es el conjunto tan farragoso, que no se ha reproducido casi nunca integro, sino con cortes que suprimen a veces más de la mitad, en las doce reediciones francesas, las diecisiete traducciones inglesas, las cinco alemanas, la holandesa y las cuatro españolas, aparecida la última en 1943. Contienen, no obstante, la totalidad del texto primitivo en la lengua original dos ediciones críticas, publicadas entrambas en París: la de Madame B. Carey, de 1874, y la de R. Foulché-Delbosc, de 1926. (Ibidem: 13).

\section{Estructura y descripción}

Por lo que respecta a la organización de la obra, la Relation du voyage d’Espagne está presentada en forma epistolar: quince cartas dirigidas a una prima que vive en Francia, probablemente en París. En las cartas Mme d’Aulnoy hace numerosos comentarios y juicios de valor sobre la nobleza española, la religión, las costumbres, la literatura, etc. Inmediatamente a su publicación, en 1691, la obra gozó de un gran éxito, siendo durante mucho tiempo un libro de referencia para la visión que los franceses tenían de España, y contribuyendo al desprestigio de nuestro país como lugar de recepción para los viajeros.

4 Cito de la edición digital de Luis Bocos y disponible online; Bocos edita el texto basándose en la primera edición en español de la Relation du voyage d’Espagne, publicada por Juan Jiménez en 1891. Incluye, asimismo, la introducción del libro Fantasías y realidades del viaje a Madrid de la condesa D’Aulnoy, del duque de Maura y de Agustín González-Amezúa (Editorial Calleja 1943), pp. 9-10. 
Una de las hipótesis más probables sobre la estancia en nuestro país, si nos basamos en las fechas en que ella finaliza cada carta, es que debió pasar en España desde el 20 de febrero de 1679 (estancia en San Sebastián) hasta el 28 de septiembre de 1680 (fin de su estancia en Madrid). La relación de fechas y lugares con que se cierra cada carta es esta: Vitoria, 24 de febrero de 1679 (2. ${ }^{a}$ carta); Burgos, 27 de febrero de 1679 (3. $\left.{ }^{a}\right)$; Lerma, 5 de marzo de 1679 (4. ${ }^{a}$ Carta, con la que finaliza el primer volumen); Aranda de Duero, 5 de marzo (5. $\left.{ }^{2}\right)$; Buitrago, 13 de marzo (6. $\left.{ }^{a}\right) ;$ San Agustín 5 , 15 de marzo (7. $\left.{ }^{a}\right) ;$ Madrid, 29 de marzo (8. $\left.{ }^{a}\right) ;$ Madrid, 27 de abril (9. ${ }^{a}$, con la que finaliza el segundo tomo); Madrid, 29 de mayo (10. $\left.{ }^{a}\right) ;$ Madrid, 27 de junio (11. $\left.{ }^{a}\right) ;$ Madrid, 25 de julio (12. ${ }^{\text {a) }}$; Madrid, 30 de agosto (13. ${ }^{\text {a)} ; ~ M a d r i d, ~} 30$ de septiembre (14. ${ }^{\text {a) }}$; Madrid, 28 de septiembre de 1680 (15. ${ }^{\text {a } y ~ f i n ~ d e l ~ V o y a g e ~ d ' E s p a g n e) . ~}$

Si el lector del libro, antes de adentrarse en él, conoce las vicisitudes respecto de la verosimilitud o falsedad del relato, no es extraño que la primera impresión que extraiga sea la de la absoluta esterilidad de dicha polémica: ya en una primera lectura se percibe la minuciosidad y exactitud de lo descrito, tanto en lo que se refiere a lugares visitados como a acontecimientos, pormenores y particularidades de las descripciones (ropas, costumbres, etc.). Sería tarea ardua tener que inventarse lugares, sucesos, descripciones de algo que no se ha visto, por muy bien que le haya sido contado o haya visto escrito. No obstante, en ocasiones no es fácil emitir un juicio acertado sobre la verosimilitud o no de las peripecias narradas en una obra, por mucho que el autor se empeñe en demostrarlo. Viene esto a colación porque la lectura del libro de Mme d’Aulnoy deja al lector español con la impresión de que, a pesar de ser el relato tan pormenorizado y exhaustivo que parece difícil encontrar una mente tan imaginativa y con tanta capacidad para la fabulación, lo escrito contiene una gran dosis de invención que hace que lo narrado o descrito no se ajuste a la verdad, bien por la exageración o bien por otros motivos 6 , aunque en su prólogo (“Au lecteur”) ella trate de justificar sus descripciones con argumentos que no sostienen cualquier tipo de análisis, como veremos seguidamente.

5 Se trata de San Agustín del Guadalix.

6 Motivos que pueden ir desde el enfado por sentirse abandonada al comienzo de su periplo, como narra el documento del archivero M. G. Ducaunnès-Duval, y que ello le agriara el carácter y le hiciera ver todo de una manera mucho más exagerada de lo normal. Que ella no se sintiera satisfecha con el trato recibido por parte de sus iguales. Que las costumbres le parecieran muy diferentes a las de su país. Que el carácter del pueblo español, menos artificial, en general, que el del francés, le pareciera vulgar y poco refinado (el modo inicial de saludar, el saludo con el que se mencionaba a la persona....). El trato menos sutil y alambicado de las damas españolas respecto de las francesas. Posiblemente una mezcla de todo ello, incluidas algunas razones más.

7 Convenio entre el narrador y su relato, se trata de la relación externa al relato o extradiegética: el autor se expresa fuera del relato por medio de prólogos, prefacios, advertencias, "avis au lecteur", "au lecteur", etc. 
AU LECTEUR

Bien qu'il ne suffisse pas d'écrire des choses vraies, mais qu'il faille encore qu'elles soient vraisemblables pour les faire croire; et que cette raison m'ait donné quelque envie d'ôter de ma Relation les Histoires qui y sont; j'en ai été empêchée par des personnes d'une Naissance et d'un Esprit si distingué, qu'il me semble qu'en suivant leurs lumières, je ne peux manquer. Je ne doute point qu'il n'y en ait d'autres, qui ne m'accusent d'avoir mis ici des Hyperboles, comme l'on a voulu le persuader à l'égard des Mémoires de la Cour d'Espagne: mais celles qui assurent avec le plus, de véhémence que l'Ouvrage n'est pas juste, pourraient être convaincues par leurs propres Lettres, d'avoir mandé à la Cour la plûpart des choses que j'ai recueillies. Je puis en avoir su quelquesunes, dont elles n'ont pas été informées, ou dont elles croient ne devoir pas convenir. Un fait n'est point faux, parce qu'il n'est pas rendu public, ou parce qu'il n'agrée point à quelque particulier. Je n'ai écrit que ce que j'ai vu; ou ce que j'ai appris par des personnes d'une probité incontestable. Je n'allègue point des Noms inconnus, ni des Gents dont la mort m'ait fourni la liberté de leur supposer des Aventures. Il faut aussì remarquer le Pays, l'Humeur et le Caractère en général de ceux dont je parle. Ces réflexions aideront à persuader que de certains Événements sont familiers dans un endroit qui n'arriveraient peut-être pas dans un autre: Mais enfin, sans démêler leurs causes, je me contente d'assurer que ce qui est dans mes Mémoires, et ce que l'on trouvera dans cette Relation, est très exact et très conforme à la vérité. (Aulnoy, 1692, vol. I: 8-10).

\section{AL LECTOR}

A veces no basta con escribir cosas verdaderas, sino que deben ser verosímiles para que se crean; este motivo me ha provocado cierto deseo de suprimir de mi Relato las historias que en él están incluidas; me lo han impedido personas de tan distinguido nacimiento y espíritu, que me parece que, al seguir su consejo, no puedo equivocarme. No dudo de que haya otros que me acusen de haber escrito exageraciones, como han querido convencerse respecto de mis Memorias de la Corte de España. Pero las que afirman con más vehemencia que la Obra no es justa, podrían convencerse por las Cartas que he enviado a la Corte, la mayor parte de las cosas que he recogido. Puedo haber sabido algunas cosas de las que no he informado, o de las que no creo que deba ni convenga hacerlo. Un hecho no es falso porque no se haga público, o porque no lo aprueba algún individuo. Sólo he escrito lo que he visto, o lo que he sabido por personas de una honradez incuestionable. No cito apellidos desconocidos, ni de gente cuya muerte me haya posibilitado la libertad de presumirles aventuras. También es necesario señalar el país, el estado de ánimo y el carácter en general de aquellos de los que hablo. Estas reflexiones ayudarán a convencer de que ciertos acontecimientos son habituales en un lugar, aunque quizá no llegarían a pasar en otro. Pero, finalmente, sin desenredar sus causas, me contento con asegurar que lo que hay escrito en mis Memorias, y lo que se encontrará en este Relato, es muy exacto y muy conforme a la verdad.

El primer argumento expuesto por la autora defiende que no basta con escribir cosas verdaderas, sino que es preciso que sean verosímiles para que sean creíbles. Si buscamos la de-

8 Cito de la segunda edición, y, para una lectura más fácil, en este y en posteriores ejemplos de la obra, he modernizado las grafías, respetando en cambio el uso de las mayúsculas. 
finición del término "vraisemblable" en el diccionario del gramático y lexicógrafo francés Pierre-César Richeleṭ se hace más fácil la comprensión del razonamiento:

Vraisemblable, s.m.Probable.Probabilité. [II faut en toutes choses chercher le vraisemblable, si on veut qu'on ajoute foi a ce qu'on débite.]

Vraisemblable, adj. Probable, qui a de la vraisemblance. [Les actions qu'on représente sur la Scène doivent être vraisemblables, sinon elles sont défectueuses. Les narrations des Orateurs doivent être vraies, ou du moins fort vraisemblables.]

Vraisemblablement, adv. Avec vraisemblance, avec probabilité. [Pour persuader, il faut parler vraisemblablement.] (Richelet, 1680: 550)
(Verosimilitud, s.m. probable. Probabilidad. [Es preciso buscar la verosimilitud en todo, si queremos tener fe en lo que decimos.]

(Verosímil, adj. Probable, que tiene verosimilitud. [Las acciones que representamos en la escena deben ser verosímiles, de lo contrario son defectuosas. Las narraciones de los oradores deben ser verdaderas, o al menos muy verosímiles].

(Posiblemente, adv. Con verosimilitud, con probabilidad. [Para persuadir, hay que hablar verosímilmente].

Pero el que la escritora se base en el argumento utilizado en retórica de que en la exposición de algún argumento se debe perseguir lo verosímil, que ocupa por su semejanza el lugar de lo verdadero, no demuestra el que los hechos que narra sean auténticos, sino que puede haberlos adaptado a lo verosímil "para un lector francés"; es decir, que su narración "va dirigida" a un lector que valorará el razonamiento teórico expuesto por ella. No obstante, el que los acontecimientos se adapten a lo verosímil no demuestra, en modo alguno, el que sean ciertos.

El hecho de que la autora haya mantenido correspondencia con la Corte, informándola de su viaje y vicisitudes, tampoco es demostrativo de la realidad de sus afirmaciones, que pueden ser "noveladas" a conveniencia, sin que haya que ir muy lejos para encontrar motivos: Ia resonancia entre los lectores de hechos "raros", "extraños" o "excéntricos" para ellos.

Sus justificaciones sobre la veracidad de su narración llevan a la autora a afirmar que escribió únicamente lo que vio, o lo que supo por personas de probidad indiscutible. Sin embargo, se trata solo de dos afirmaciones que no se sustentan en argumentos sólidos, ya que ¿qué le impedía deformar o distorsionar la realidad de lo visto o lo que le habían contado?

9 La primera edición del Dictionnaire de l'Académie Française no se publicaría hasta tres años más tarde de la aparición del libro de Mme d'Aulnoy, es decir, en 1694. El Thresor de la langue francoise de Jean Nicot solo incluye el término "veritable", sin añadir matiz alguno (Veritable, Cultor veritatis, Veridicus, Verax). 
Finalmente, sustenta sus descripciones en la idiosincrasia del país, el estado de ánimo y el carácter en general de aquellos de quienes habla, argumento sin consistencia alguna, ya que ¿para qué convencer a sus compatriotas los franceses de algo según ella tan notorio, evidente y difundido como el carácter y costumbres del pueblo español?

Resumiendo, el prólogo (“Au lecteur”) de Mme d’Aulnoy no contiene argumento alguno que certifique o apoye lo que afirma, aunque el lector puede deducir que lo narrado sobre la clase noble y la corte (la mayor parte de su narración) es más verosímil que los pasajes en que describe al pueblo llano; es decir, que la simpatía hacia una clase social más cercana a la suya influye en la descripción de los hechos.

Pero, a pesar de que no solo la propia escritora, sino también otras opiniones quieran justificar la imparcialidad de la narración, ¿cómo no ver exageradas, desfiguradas o distorsionadas algunas descripciones del país que visitó, sus gentes y costumbres tras leer detenidamente algunos pasajes de sus cartas, como los fragmentos de las cartas que pongamos como ejemplo de su impresión absolutamente negativa de España, sus habitantes y sus costumbres ${ }^{10}$ ? No es necesario transcribir muchos pasajes para enjuiciar la opinión de Mme d’Aulnoy, pues ya desde la primera carta encontramos una referencia completa a nuestro país (en este caso San Sebastián) y sus habitantes y costumbres; el fragmento, a pesar de su longitud, merece la pena para conocer la opinión de la escritora desde el inicio de su obra:

Je trouvai de l'autre côté de cette Rivière un Banquier de S. Sebastien à qui j'étais recommandée; il m'attendait avec deux de ses parents; les uns \& les autres étaient vêtus à la Schomberg, c'est proprement à la manière de France, mais d'une manière ridicule, les Justaucorps sont courts \& larges, les manches ne passent pas le coude, \& sont ouvertes par devant; celles de leurs chemises sont si amples qu'elles tombent plus bas que le Justaucorps. Ils ont des Rabats sans avoir de colets de pourpoint, des Peruques où il y a plus de cheveux qu'il n'en faut pour en faire quatre
Encontré al otro lado de este río a un banquero de San Sebastián al que iba recomendada; me estaba esperando con otras dos personas de su familia; unos y otros iban vestidos al estilo Schomberg, es propiamente al estilo de Francia, pero de una manera ridícula, las levitas cortas y anchas, con mangas terminadas en el codo $y$ abiertas por delante; las de las camisas tan amplias que sobresalen de la levita. Tienen solapas sin lazos de cinta, pelucas en las que hay más pelo del que se necesitaría para hacer cuatro, bien hechas, y el pelo es más crespo que la crin

10 El método utilizado para analizar los pasajes propuestos se basa en la estilística del investigador alemán Leo Spitzer, considerado por el propio crítico como estructural; es decir, analizar los rasgos lingüísticos que afectan a las actitudes y circunstancias puramente literarias de la obra, operación que Spitzer no ponía en práctica al azar, sino que se apoyaba siempre en sus múltiples e ilimitadas lecturas para establecer admirables comparaciones entre las obras literarias. Así pues, se trata básicamente de un análisis filológico, basado solo y únicamente en la propia inmanencia del texto, sin ninguna actitud crítica preconcebida. 
autres bien faites, \& ces cheveux sont plus frissés que du crin bouilli; l'on ne peut voir des gens plus mal coiffés. Ceux qui ont leurs Cheveux les portent fort longs \& fort plats; ils les séparent sur le côté de la tête, \& en passent une partie derrière les oreilles: mais quelles oreilles, bon Dieu! je ne crois pas que celles de Midas fussent plus grandes, \& je suis persuadée que pour les allonger, ils se les tirent étant encore petits; ils y trouvent sans doute quelque sorte de beauté. Mes trois Espagnols me firent en mauvais Français de très grands \& très ennuyeux compliments; nous passâmes le Bourg de Tran, qui est à peu prés à un quart de lieue de la Rivière, \& nous arrivâmes ensuite à Irun, qui en est éloigné d'un autre quart de heure. Cette petite Ville est la première d'espagne (sic) que l'on trouve en sortant de France. Elle est mal bâtie. Les rues en sont inégales, \& il n'y a rien dont on puisse parler; Nous entrâmes dans l'Hôtellerie par l'Ecurie, où donne le pied du degré par ou l'on monte à la Chambre: c'est l'usage du Pays. Je trouvai cette Maison fort éclairée par une quantité de Chandelles qui n'étaient guère plus grosses que des alumettes; il y en avait bien quarante dans ma Chambre, attachées sur des petits morceaux de bois, l'on avait mis au milieu un brasier plein de noyaux d'Olives en charbon, pour ne pas fire mal à la tête.

L'on me servit un grand souper que les Galands Espagnols m'avaient fait preparer: mais tout était si plein d'ail, de safran \& d'épice, que je ne pus manger de rien; \& j'aurais fait fort mauvaise chère si mon Cuisinier ne me eût accommodé un petit Ragoût de ce qu'il pût trouver plutôt prêt. (Aulnoy, 1692, vol. I: 22-24). de caballo hervida; no se puede ver gente peor peinada. Los que tienen pelo lo llevan muy largo y muy lacio; se lo separan en dos mitades a un lado de la cabeza, y se pasan una parte detrás de las orejas: ipero qué orejas, Dios mío! No creo que las orejas de Midas fueran más grandes, y estoy seguro de que, para alargarlas, se las estiran cuando aún son pequeños; probablemente encuentran algún tipo de belleza en eso.

Los tres españoles me hicieron en mal francés grandes y muy molestos cumplidos; pasamos el caserío de Tran, que está a un cuarto de milla del río, y llegamos luego a Irún, que está a otro cuarto de hora de distancia. Este pueblo es el primero en España que uno encuentra al salir de Francia. Está mal construido. Las calles son desiguales y no hay en él nada digno de ser recordado. Entramos en la posada por el establo, de donde arranca la escalera que lleva a la habitación: es la costumbre del país. La casa estaba iluminada por una gran cantidad de velas tan delgadas como briznas; había cuarenta en mi habitación, sujetas a palitos atados a pequeños trozos de madera, y en el centro había un brasero lleno de huesos de aceitunas secos, para evitar el dolor de cabeza que produce el carbón de leña.

Me sirvieron una gran cena que los galantes españoles habían mandado preparar para mí: pero todo tenía tanto ajo, azafrán y especias, que no pude comer nada; y habría pasado mucha hambre si mi cocinero no me hubiera guisado lo que pudo encontrar a mano.

Analizando el fragmento elegido, la primera curiosidad que encontramos es la descripción de las vestimentas de los españoles que acogen a la viajera: estos van vestidos "a lo Schomberg". Se trata de Frédéric-Armand de Schomberg, conocido como "le maréchal de Schomberg" (1615-1690). Nacido en Heidelberg, haría carrera militar en Francia siendo uno de los generales más conocidos en Europa, sirviendo sucesivamente a Luis XIII y entre 1639-1650 a 
Frédéric-Henri de Orange y luego a su hijo Guillermo II de Orange-Nassau. De vuelta en Francia compró el cargo de capitán, participando en la guerra contra España. Sería nombrado Mariscal de Campo en 1652 y teniente general en 1655, ayudando al rey Alfonso VI de Portugal a vencer a los españoles en la denominada Guerra de Restauración. Ha pasado a la literatura por mandar las tropas francesas que ayudarían al ejército portugués en la guerra contra España, telón de fondo de las Lettres de la Portugaise traduites en Français (1699), en las que la monja Mariana Alcoforado escribe cinco cartas al caballero Chamilly, con el que parece que había mantenido amores en el Convento de la Concepción de la ciudad portuguesa de Bejaํ.

No solo la vestimenta es inadecuada en los españoles, sino que tampoco saben llevar las pelucas, estando la gente en general muy mal peinada, resaltando en ellos sus grandes orejas, las que, según la escritora, se les estiran a los niños.

Los tres españoles que la reciben, a los que se supone burgueses y de familias pudientes, hablan muy mal francés, siendo muy pesados en sus cumplidos.

El pueblo de Irún está muy mal construido, con calles poco armoniosas o típicas, sin que merezca la pena recordarse nada de él. En las posadas, las velas son ridículas y la lumbre se alimenta con huesos de aceituna ${ }^{12}$.

La cena, como era proverbial al juzgar la gastronomía española en los extranjeros que visitaban España, a pesar de ser muy abundante no era comestible para la autora dada la gran cantidad de ajo, azafrán y especias con que estaban adobados los alimentos. Para explicar lo poco que ha comido, Aulnoy utiliza la expresión "faire mauvaise chère", equivalente a la más actual "ne pas manger à sa faim", y que tiene su origen en el hambre que pasaba la gente a causa de la Guerra de los Cien Años: únicamente “un bon repas” les provocaba la sonrisa (chère, del latín cara).

Nada hay que parezca complacer a nuestra visitante, que no escatima ninguna apreciación negativa sobre el país que visita, sus habitantes y costumbres, a pesar de que reconozca que se esfuerzan por tratarla con afabilidad y respeto, lo que nos induce a extraer la curiosa deducción

11 Aunque la Paz de los Pirineos de 1659 firmada entre Francia y España privaba a Portugal de la asistencia económica y material en soldados, dos años más tarde Francia volvió a ayudar a los portugueses con dinero y tropas al mando del mariscal francés de origen alemán Schomberg: en 1665 el marqués de Caracena fue derrotado en la batalla de Montes Claros o de Vila Viçosa por el portugués Marialva y Schomberg, perdiéndose definitivamente para los reyes españoles Portugal con sus colonias. Cf. Á. García Calderón / M. Á. García Peinado: Alcoforado / Barret Browning: Cartas Portuguesas / Sonetos de la Portuguesa (Edición, estudio y traducción), Granada: Editorial Comares (Colección Mezquita), 2008.

12 Lo cual se ha revelado en nuestros días como un buen combustible para las chimeneas, calderas y similares. 
de que sus juicios y opiniones confirman la veracidad de su viaje: de haber escrito sin haber llevado a cabo su viaje, influida por opiniones y libros de otros viajeros anteriores, sus críticas habrían sido mucho más benignas, ya que siempre hubiera dejado algún atisbo para la duda.

\section{Conclusión}

Antes de la llegada de los escritores románticos franceses, España era conocida por el teatro del Siglo de Oro, la picaresca y los pintores. Hasta entonces, la fama de nuestro país, sus gentes y costumbres era muy negativa, de ahí que no fuera nada extraño el que Mme d’Aulnoy no escatimara burlarse y satirizar sobre lo que veía, dada la predisposición de ella misma y de sus posibles lectores, a los que habría defraudado pareciéndole su relato ajeno a la realidad tal como ellos la concebían.

En el siglo XVIII los filósofos del Siglo de las Luces siguieron contemplando con desconfianza, e incluso a veces con horror, el país para ellos "de la Inquisición".

Sería a comienzos deI XIX, motivado posiblemente por la feroz resistencia de los españoles a los ejércitos napoleónicos, cuando se revelaría en Francia el orgullo del pueblo español, su arraigo a su suelo y su amor por la libertad. Así, para la mayor parte de los franceses, España es un descubrimiento relativamente reciente, concretamente del Romanticismo. Serían grandes escritores (Mérimée, Gautier, Dumas, Hugo, George Sand...) los que pondrían de moda nuestro país, apreciando la belleza de lo que para su sensibilidad era extraño. Dos testimonios son suficientes para contemplar una visión diferente de la de Mme d’Aulnoy, el primero uno de los poemas que forman la obra Espagne, de Théophile Gautier (1845):

DANS LA SIERRA

J'aime d'un fol amour les monts fiers et sublimes! Les plantes n'osent pas poser leurs pieds frileux Sur le linceul d'argent qui recouvre leurs cimes; Le soc s'émousserait à leurs pics anguleux.

Ni vigne aux bras lascifs, ni blés dorés, ni seigles, Rien qui rappelle l'homme et le travail maudit.

Dans leur air libre et pur nagent des essaims d'aigles,

Et l'écho du rocher siffle l'air du bandit.

Ils ne rapportent rien et ne sont pas utiles; Ils n'ont que leur beauté, je le sais, c'est bien peu. Mais, moi,jelespréfèreauxchampsgrasetfertiles, Qui sont si loin du ciel qu'on n'y voit jamais Dieu!
EN LA SIERRA

iAmo con amor loco el monte fiero, excelso! La planta allí no posa sus pies tan frioleros en el manto plateado que recubre su cima; se mellaría el arado en sus picos de aristas.

Ni la vid voluptuosa, trigo de oro o centeno, nada que evoque al hombre y al trabajo maldito. En su aire libre y puro bate un enjambre de águilas,

la roca lleva el eco de aroma a bandolero.

De nada participan y en nada son valiosos; sólo son su belleza, ya sé que es muy poco. ¡Pero yo los prefiero a campos verdes, fértiles, tan lejanos del cielo que nunca ven a Dios! 
Gautier viajaría por España en 1840, volviendo entusiasmado de la tierra que denominaría "sauvage contrée" y reuniendo sus impresiones en un libro de viajes: Tra los montes (1843), que reedita dos años después con el título de Voyage en Espagne, desarrollándolos en los poemas de España, que aparece por vez primera en la recopilación Poésies complètes de 1845.

El gran Victor Hugo, que debe su relación con España a su padre el general del ejército de Napoleón, Joseph Léopold Sigibert Hugo, en la época de la campaña de España, dejaría un testimonio muy emotivo de sus vivencias en nuestro país, en el poemario L'art d'être grand-père, volumen de 27 poemas dedicados a sus nietos Jeanne et Georges, publicado en 1877; incluye un poema titulado "Les fredaines du grand-père enfant" (1811), del que extracto unos versos:

\begin{tabular}{l|l}
\hline $\begin{array}{l}\text { Dans cette Espagne que j'aime, } \\
\text { Au point du jour, au printemps, } \\
\text { Quand je n'existais pas même, } \\
\text { Pepita -j'avais huit ans- }\end{array}$ & $\begin{array}{l}\text { En esta España a la que amo, } \\
\text { al alba, en la primavera, } \\
\text { cuando ni aún vivía, } \\
\text { Pepita -yo a mis dieciocho años- }\end{array}$ \\
$\begin{array}{l}\text { Me disait: -Fils, je me nomme } \\
\text { Pepa; mon père est marquis.- } \\
\text { Moi, je me croyais un homme, } \\
\text { Étant en pays conquis. }\end{array}$ & $\begin{array}{l}\text { Me decía: -Niño, me llamo } \\
\text { Pepa me creía un hombre, }\end{array}$ \\
\hline
\end{tabular}

\section{Bibliografía citada}

Aulnoy, Mme DE, 1691: Relation du voyage en Espagne, Paris: Claude Barbin.

Aulnoy, Mme de, 1692: Relation du voyage d'Espagne [Seconde Édition], La Haye: Henri van Bulderen, 3 vols.

Aulnoy, Mme de, 1693: Relation du voyage d'Espagne, Lyon: Anisson \& Possuel, 2 vols.

Aulnoy, Mme De, 1874-1876: La Cour et la Ville de Madrid vers la fin du XVIle siècle. Relation du voyage d'Espagne, édition nouvelle, revue et annotée par Mme B. Carey, Paris: Plon.

Aulnoy, Mme de, 1891: Relación que hizo de su viaje por España la Señora Condesa D'Aulnoy en 1679, Madrid: Juan Jiménez Librero Editor.

Aulnoy, Mme de, 1998 [1892]: Relación que hizo de su viaje por España la Señora Condesa D'Aulnoy en 1679. Primera versión española. Nueva edición, aumentada con un precioso retrato de Mme d'Aulnoy y un detallado Índice de materias, Madrid: Tipografía Franco-Española [reimpresión: Valencia, Librerías Paris-Valencia]. 
Aulnoy, Mme De, 1926: Relation du voyage d'Espagne, avec une introduction et des notes par Raymond Foulché-Delbosc, Paris: Klincksieck.

Aulnoy, Mme de, 1942: Un viaje por España en 1679 por la Condesa d'Aulnoy [traducción y nota preliminar de Luis Ruiz Contreras], Madrid: Ediciones La Nave.

Aulnoy, Mme De, 1999 [1952]: Relación del viaje de España [traducción de José García Mercadal] en José GARCÍA MERCADAL: Viajes de extranjeros por España y Portugal, Valladolid: Junta de Castilla y León, vol. IV, 10-281.

Aulnoy, Mme de, 1962: Viaje por España en 1679 y 1680. Cuentos feéricos, 2 vols. [traducción y notas por María Corominas y Mercedes M. Villalta], Barcelona: Ediciones Iberia.

Aulnoy, Mme de, 1986: Relación del viaje de España. Según edición de G. Mercadal. Prólogo de Lorenzo Díaz, Madrid: Akal.

Aulnoy, Mme de, 2000: Viaje por España en 1679, prólogo de J. M. Díez Borque [traducción de Marta Corominas y Mercedes M. Villalta], Barcelona: Círculo de lectores.

Aulnoy, Mme de, 2000: Relación de viaje por España [edición y traducción de Pilar Blanco y Miguel Ángel Vega, introducción de M. Á. Vega], Madrid: Cátedra.

Aulnoy, Mme de, 2005: Relation du voyage d’Espagne [éd. María Susana Seguin], Paris: Desjonquères.

Courteault, Paul, 1936: “Le voyage de Mme d’Aulnoy en Espagne”, Bulletin hispanique 38 (3), 383-384.

Dumas, Alexandre, 1874 [1861]: De Paris à Cadix: Impressions de voyage, Paris: A. le Vasseur et Cie. (nouvelle édition: Michel Lévy Frère).

Foulche-Delbosc, Raymond, 1991 [1896]: "Bibliographie des voyages en Espagne et en Portugal”, Revue Hispanique III, Madrid, edición facsímil, Julio Ollero Editor.

FreIXA, Consol, 1994: “España en las geografías británicas del siglo XVIII”, Estudios geográficos 55 (214), 59-79.

Garcia Calderón, Ángeles, Miguel Ángel García Peinado, 2008: Alcoforado / Barret Browning: Cartas Portuguesas / Sonetos de la Portuguesa (Edición, estudio y traducción), Granada: Editorial Comares.

Losada Goya, José Manuel, 1999: Bibliographie critique de la littérature espagnole en France au XVIle siècle. Présence et influence, Genève: Droz. 
Martínez, Marga, 2004: "Viajeros extranjeros por España: Francis Carter”, Boletín de la Sociedad Geográfica Española 17 (Mundo maya).

Maura y Gamazo, Gabriel (Duque de Maura), Agustín González-Amézua, s. f. (años 40): Fantasías y realidades del viaje a Madrid de la Condesa d'Aulnoy, Madrid: Ed. Saturnino Calleja.

Morel-Fatio, Alfred, 1888: "Comment la France a connu et compris l'Espagne depuis le Moyen Âge jusqu'à nos jours”, Études sur l'Espagne, Paris: F. Wieweg Libraire-Éditeur.

RICHelet, Pierre (1680): Dictionnaire françois contenant les mots et les choses, plusieurs nouvelles remarques sur la langue françoise: Ses Expressions Propres, Figurées \& Burlesques, la Prononciation des Mots les plus difficiles, les genres des Noms, le Regime des Verbes avec Les termes les plus connus des Arts \& des Sciences, le tout tiré de l'usage et des bons auteurs de la langue françoise, Genève: Chez Jean Herman Widerhold.

TAYNE, Hippolyte, 1903: "Madame d'Aulnoy, Voyage en Espagne" en Derniers essais de critique et d'histoire [troisième édition], París: Hachette. 